\title{
Erratum to: Template-free electrochemical synthesis of tin nanostructures
}

\author{
David T. Mackay ${ }^{1}$ Matthew T. Janish ${ }^{2,3}$ - Uttara Sahaym ${ }^{1} \cdot$ Paul G. Kotula ${ }^{4}$ • \\ Katherine L. Jungjohann ${ }^{4}$ C. Barry Carter ${ }^{2,3,4,5} \cdot$ M. Grant Norton ${ }^{1}$
}

Published online: 28 December 2015

(C) Springer Science+Business Media New York 2015

\section{Erratum to: J Mater Sci (2014) 49:1476-1483 DOI 10.1007/s10853-013-7917-1}

The images presented in Fig. 1a and b of Mackay et al. [1] were not obtained from samples produced using the specific conditions described in the Experimental section on page 1477. Replacement figures from samples prepared under the conditions described in the text [1] using a deposition current of $35 \mathrm{~mA} / \mathrm{cm}^{2}$ are provided in this
Erratum. Owen and Norton have recently shown [2] that nanoneedle structures can be produced using a range of deposition conditions; the material shown in the corrected figure was obtained with the best known conditions at the time of submission. The analysis of the structures and the way that these needles interact with, e.g., Li [3] are not affected by the error since the analysis in this paper was carried out on material prepared under the conditions described in [1].

The online version of the original article can be found under doi:10.1007/s10853-013-7917-1.

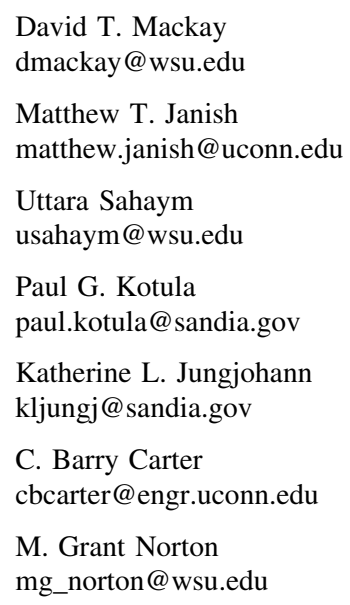

1 School of Mechanical and Materials Engineering, Washington State University, Pullman, WA 99164, USA

2 Department of Materials Science and Engineering, University of Connecticut, Storrs, CT 06269, USA

3 Institute of Materials Science, University of Connecticut, Storrs, CT 06269, USA

4 CINT, Sandia National Laboratories, PO Box 5800, Albuquerque, NM 87185, USA

5 Department of Chemical and Biomolecular Engineering, University of Connecticut, Storrs, CT 06269, USA 

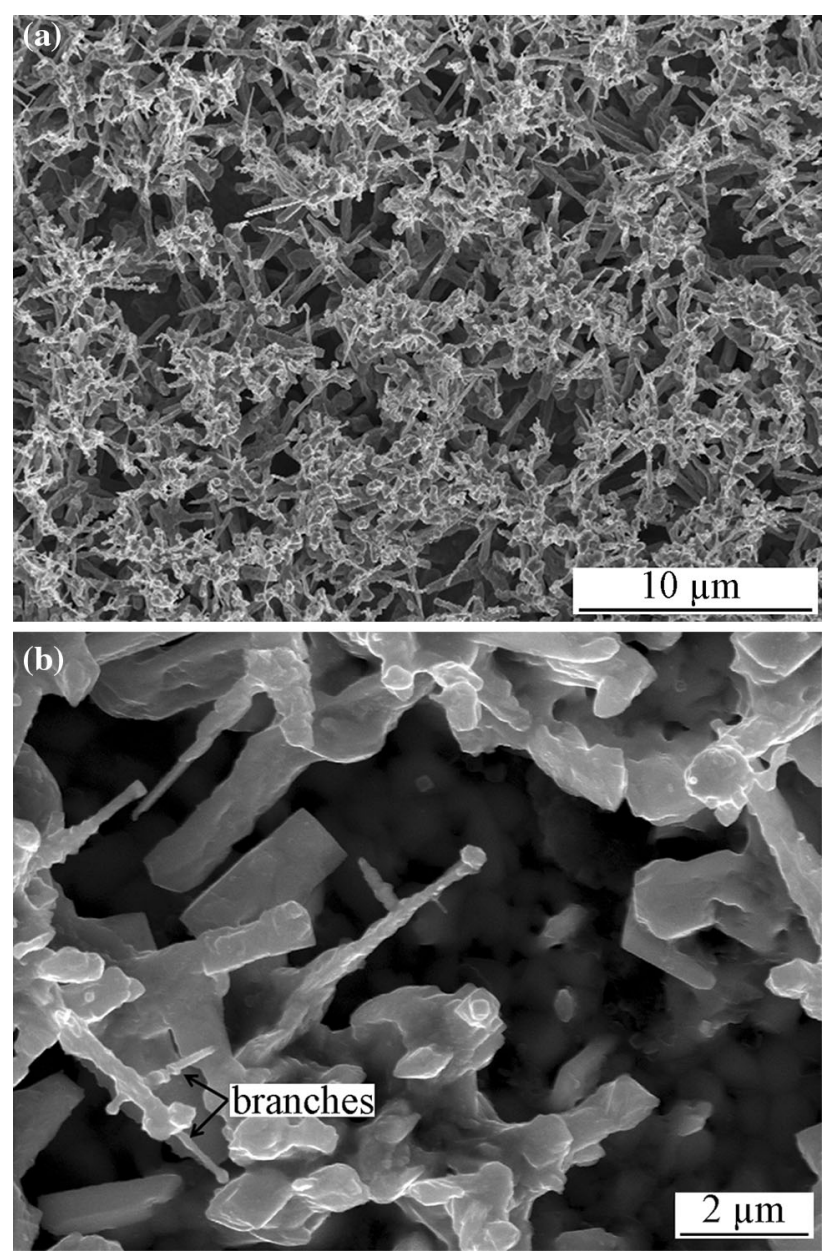

Fig. 1 a SEM image showing tin nanoneedles formed by electroplating onto copper substrates. b Higher-magnification image of the same sample showing branch points formed during nanoneedle growth

\section{References}

1. Mackay DT, Janish MT, Sahaym U, Kotula PG, Jungjohann KL, Carter CB, Norton MG (2014) Template-free electrochemical synthesis of tin nanostructures. J Mater Sci 49:1476-1483. doi:10. 1007/s10853-013-7917-1

2. Owen CD, Norton MG (2016) Growth mechanism of one dimensional tin nanostructures by electrodeposition. J Mater Sci 51:2577-2588. doi:10.1007/s10853-015-9323-3

3. Janish MT, Mackay DT, Liu Y, Jungjohann KL, Carter CB, Norton MG (2016) TEM in situ lithiation of tin nanoneedles for battery applications. J Mater Sci 51:2589-2602. doi:10.1007/s10853-0159318-0 